\title{
Astronomical Content in Rongorongo Tablet Keiti
}

Rafal M. Wieczorek

\section{(2) OpenEdition \\ Journals}

\section{Electronic version}

URL: http://journals.openedition.org/jso/6272

DOI: $10.4000 /$ jso.6272

ISSN: $1760-7256$

Publisher

Société des océanistes

\section{Printed version}

Date of publication: 30 June 2011

Number of pages: 5-16

ISBN: 978-2-85430-030-7

ISSN: 0300-953x

\section{Electronic reference}

Rafal M. Wieczorek, " Astronomical Content in Rongorongo Tablet Keiti », Journal de la Société des

Océanistes [Online], 132 | 1er semestre 2011, Online since 30 June 2014, connection on 19 April 2019.

URL : http://journals.openedition.org/jso/6272 ; DOI : 10.4000/jso.6272 


\title{
Astronomical Content in Rongorongo Tablet Keiti
}

by

\author{
Rafal M. WIECZOREK
}

\begin{abstract}
The field of rongorongo research: the study of Easter Island's native script is in a peculiar state at the moment. While relative progress has been made in structural and statistical analysis in the last decades, at the level of both single glyphs as well as entire texts, little to no advancement has been achieved in the actual decipherment. To shed new light on rongorongo research, a hypothesis regarding the contents of tablet Keiti, one of the 25 obtained artifacts, is proposed. The content, as well as the meaning, of all but one of these 25 rongorongo texts is still unknown. In this publication, an interpretation for the recto side of tablet Keiti is presented. It is argued that the tablet contains astronomical observations or instructions regarding the Rapa Nui lunar calendar, and is similar in content to the only other rongorongo text whose function has been partially ascertained: tablet Mamari. If the calendrical contents of this artifact were confirmed, this would be a major boost to our understanding of Oceania's only native script.
\end{abstract}

Keywords: Rongorongo text E, Tablet Keiti, Easter Island, Rapa Nui language, lunar calendar, sequence alpha 1-10

There are three main obstacles to any significant progress in the decipherment of Easter Island's rongorongo script. The first is the fact that Old Rapa Nui language in which the tablets are most probably written is considerably different from its modern equivalent and we have only limited knowledge of it (Fischer, 1992). The second is the small extent of the rongorongo corpus, which was collected in

\section{RÉSUMÉ}

Le champ de recherche de Rongorongo, l'etude de l'écriture native de l'ìle de Pâques, est aujourd'hui dans une situation particulière. Si, pendant les dernières décennies, un progrès relatif a été fait en ce qui concerne l'analyse structurelle et statistique au niveau des hiéroglyphes isolés comme du texte entier, presque aucune avancée n'a été obtenue dans le déchiffrement réel. Pour la recherche de Rongorongo, une hypothèse concernant le contenu de la tablette Keiti, une des 25 auvres gravées, est proposée. Le contenu, tout comme la signification de l'ensemble des textes de Rongorongo, à l'exception d'un seul, est encore inconnu. Dans cat article, une interprétation du recto de la tablette Keiti est présentée. On propose qu'elle offre des observations astronomiques ou des instructions à propos du calendrier lunaire de Rapa Nui et qu'elle est similaire dans son contenu à l'unique texte de Rongorongo dont la fonction a été partiellement vérifiée : la tablette Mamari. Si les contenus astronomiques de cette ouvre gravée étaient confirmés, il s'agirait d'un grand pas en avant vers notre compréhension de l'unique écriture native d'Océanie.

Mots-CLÉs : Rongorongo texte E, tablette Keiti, Île de Pâques, langue de Rapanui, calendrier lunaire, suite alpha 1-10

random fashion, it is not known whether it under- and/or over-represents particular genres (Melka, 2009b), and is in overall composed of less than 15000 glyphs (Pozdniakov, 1996: 290). The last being the lack of context with which we can interpret the text, for example an illustration of an animal or other object accompanying a text, which might be interpreted as a name for that animal and therefore trigger

* Flint Center, University of Southern Denmark, DK 5230 Odense M, rafal@ifk.sdu.dk 
plausible speculations for the reading of each glyph (Englert, 1948).

The only context of sign sequence, whose meaning we can understand with some degree of certainty are three lines of side " $\mathrm{a}$ " of tablet Mamari, which contains a lunar calendar, first described by Barthel (1958: 242-247). It is worthy of notice that these are only three lines out of a total of 28 contained on the tablet Mamari, which is only one of the 25 apparently authentic rongorongo objects which have survived to this day (Fischer, 1997). The identification of this sequence led to some seemingly possible phonetic speculations about a few rongorongo glyphs (Guy, 1990).

Eventual verification of such a speculation would be possible only if context for some other sequences were established. At present it seems that this can be achieved only by structural and possibly semantic analysis (Guy, 1982, 1985; Sproat, 2003; Horley, 2005, 2007; Berthin \& Berthin, 2006; Pozdniakov \& Pozdniakov, 2007; Melka, 2008).

One such possible identification is the interpretation of the line Gv6 on the "Small Santiago Tablet " (tablet G) as a form of genealogy (Butinov and Knorozov, 1957). After 50 years, this proposition is still considered plausible (Pozdniakov, 1996; Guy, 2003), but to this day we have no new knowledge that would allow us to disprove or prove this hypothesis, even though it was slightly refined by Guy (1998c).

Mutually exclusive to Butinov and Knorozov's (1957) idea is the one proposed for similar sequences occurring on the "Santiago Staff" (item I), and dubbed by its author the " procreation triads " (Fischer, 1995). In the last fifteen years, this idea has been severely criticized by various authors (Pozdniakov, 1996; Guy, 1998a,b; Robinson, 2002: 241; Sproat, 2003). Scrupu- lous structural examination of the "Santiago Staff » text revealed that Fischer's idea cannot be correct in at least $40 \%$ of cases (Melka, 2009a: 43). One must conclude that the likelihood of this hypothesis is much smaller than Butinov and Knorozov's (1957).

\section{Tablet Keiti}

The rongorongo tablet "Keiti " was one of the rongorongo items collected by father Roussel in the year 1870 and sent to bishop Jaussen in Tahiti (Fischer, 1997: 410). Before sending this tablet to Europe, Jaussen made exact copies of it, which proved very valuable since the original was later destroyed during the First World War (Barthel, 1958: 20).

In a recent article, Melka (2008) put tablet Keiti (dubbed « tablet E » under Barthel's (1958) alphabetic designation) under careful structural analysis. He identified three types of glyphic sequences that repeat several times in the recto side of the tablet, which were earlier independently retrieved by Sproat (2003), Horley (2007: 26) and partially by Butinov and Knorozov (1957: 10). However, Melka (2008) submitted them to more dedicated study, and named each one of them; sequence alpha 1-10, sequence beta 1-7 and sequence gamma 1-10 according to the number of times they are repeated on the tablet (figure 1). The nature of sequence beta seems to be different than that of sequences alpha and gamma, as the former is a short sequence repeated several times in-line, whereas the later are dispersed throughout the whole tablet (figure 1). Also, sequence alpha contains within itself a string of glyphs identical to sequence gamma. Analysis of the verso side of the tablet, performed by the same author (Melka, 2008), showed

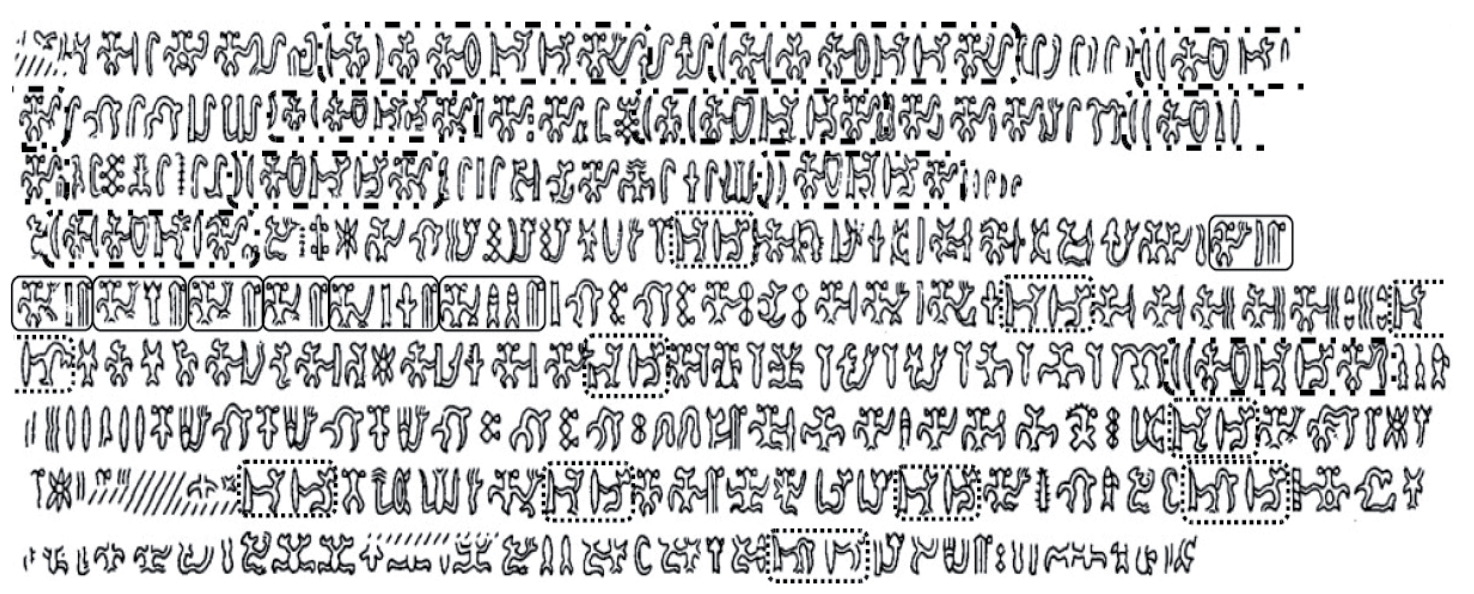

The lines have been rearranged to reflect English reading order: Er1 at top, Er9 at bottom.

Identified repeated sequences are marked with cartouches: bold dashed line - sequence alpha 1-10, filled line - sequence beta 1-7, dashed line - sequence gamma 1-10 (based on Melka 2008).

Figure 1. - The recto of Tablet $\mathrm{E}$ as traced by Barthel (1958). Image adapted from Wikipedia after Barthel (1958) 
no repetitious sequences. The only characteristic feature of the verso side was the highly frequent occurrence of the compound glyph 380.001 (this feature of some rongorongo texts was actually the first ever structural notion of the rongorongo glyphs, noticed by Harrison in the XIX ${ }^{\mathrm{th}}$ century (Harrison, 1874: 379), and later elaborated by other researchers, e.g. Barthel (1958: 306-307), Pozdniakov (1996: 301), Horley (2007: 26-27). From his analysis, Melka (2008) concluded that the two sides of the tablet "Keiti " represent different genres (in his own words " different textual sub-categories "), probably dealing with different subjects. Such a notion justifies the analysis of each side of the tablet separately, without reference to one another. In this work I will deal only with the recto side of tablet «Keiti » without further reference to the verso side.

\section{Sequence alpha 1-10}

The most prominent repetitious sequence identified by Melka (2008: 161-162) is the so called sequence alpha 1-10 (see figure 1 for its distribution on the tablet). This sequence is composed of variations of a core structure which can be described, using Barthel's modified transcription, as: 040/041-040/041-300.028x-004.430$022.430 y-203$. Barthel's transcription modified by the Rongorongo Commission of the "Cercle d'études sur l'Île de Pâques et la Polynésie " (CEIPP) is used throughout the article based on

\begin{tabular}{|c|c|c|c|}
\hline Sequence drawing & Barthel's (1958) coding & $\begin{array}{l}\text { Position on } \\
\text { the tablet }\end{array}$ & $\begin{array}{l}\text { Melka’s (2008) } \\
\text { designation }\end{array}$ \\
\hline ( & $\frac{040.300-041-300 \mathrm{y}-300.024-}{004.430-022.430 \mathrm{y}-206.063}$ & Er1 & alpha 1 \\
\hline 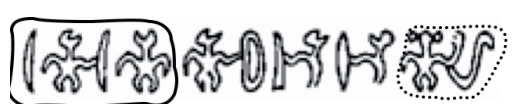 & $\frac{040-300.040-300 y-300.024-}{004.430-022.430 y-201.063}$ & Er1 & alpha 2 \\
\hline ก) & $\begin{array}{l}040-040-300.028 \mathrm{x}-004.430- \\
022^{*}-203 s\end{array}$ & Er1-2 & alpha 3 \\
\hline 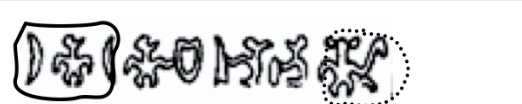 & $\frac{041-300-040-300.028 x-004}{430 ?-022.380 y-203 s}$ & Er2 & alpha 4 \\
\hline 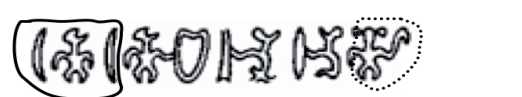 & $\frac{040-300-040-300.028 x-}{004.430-022.380 y-203}$ & Er2 & alpha 5 \\
\hline 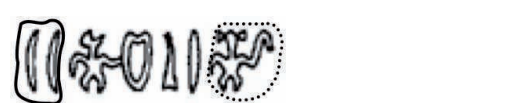 & $\frac{040-040-300.028 \mathrm{x}-004-022^{*}-}{203 s}$ & Er2-3 & alpha 6 \\
\hline 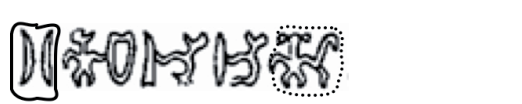 & $\frac{041-040-300.028 x-004.430 y-}{022.380 y-203 s}$ & Er3 & alpha 7 \\
\hline (D) & $\begin{array}{l}041-041-300.028 x-004.430- \\
022.380 y-203\end{array}$ & Er3 & alpha 8 \\
\hline 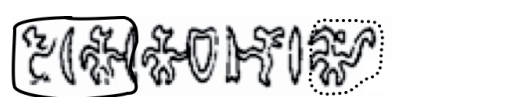 & $\frac{385-040-300.040-300.028 x-}{004.430-022-520 f y .063}$ & Er4 & alpha 9 \\
\hline (1) 2ี० & $\begin{array}{l}\frac{040-040-300.028 x-004.430-}{022.380 y-204.077} \\
0 .\end{array}$ & Er6 & alpha 10 \\
\hline
\end{tabular}

The alpha-alpha 'moon instruction sequence' is given in filled line cartouche in first column and as underline text in second column. The final alpha-gamma '200-like glyph' is given in dashed line cartouche in first column and as bold text in second column.

The allographically unchanging middle sequence alpha-beta is left unmarked

TABLE 1. - The structure of sequences alpha 1-10. 
the material published on the website www.rongorongo.org (CEIPP , 2005).

I propose structurally dividing the sentence 040/041-040/041-300.028x-004.430$022.430 \mathrm{y}-203$ further into three sub-sequences; alpha-alpha: a sequence of two moons facing either right or left with conditional anthropomorphic descriptors; sequence alpha-beta: composed of glyphs 300.028x-004.430-022.430y although some components of this sequence might seem variable, it will be demonstrated later that close examination of their physical, i.e. place on the wooden tablet, placement allow to conclude that this sequence remains semantically unalterable; the final sub-sequence alpha-gamma: comprised solely of an anthropomorphic glyph with various suffixes. This further break down of sequences alpha1-10 is illustrated in Table 1.

\section{On sequence alpha-alpha}

This sequence is composed of two moons facing either right or left, i.e. glyphs 040 and 041, in all possible combinations: right-right, rightleft, left-right and left-left. In some cases the moons are accompanied and/or held by one or two anthropomorphic figures (glyph 300).

Melka (2008) identified sequence alpha as starting from the glyph of the first moon. His method for identifying sequence alpha 1-10 was by comparison of similar strings of glyphs. Such a method fails to identify glyphs that are protruding from a repetitious sequence either before it or after it that might have been conceived by the original scribe as an integral part of a phrase.

In my opinion, such a situation might have occurred with at least one such alpha-alpha sequence: sequence alpha-9, which starts in the beginning of line Er4 is preceded in this line by only one other glyph, glyph 385, representing an anthropomorphic figure. In no other case is sequence alpha preceded by an anthropomorphic figure, but anthropomorphic figures are observed as parts of other alpha-alpha sequences (for example alpha 1 and alpha 5).

It might be argued that this glyph is not likely a direct continuation of line Er3, which ends unusually in wedging between lines 2 and 4 . If glyph 385 were a direct continuation of glyphs 022-022-063-041-063, which end line Er3, it would most likely also be written in the wedge between lines Er2 and Er4. As can be seen in figure 2 the scribe could easily have designed the wedging in line Er2 in such a way to have space for one more glyph. The scribe, however did not do this, most likely because the next glyph (glyph 385) starts a new sentence or a new word, not closely connected with previous sentence or word.

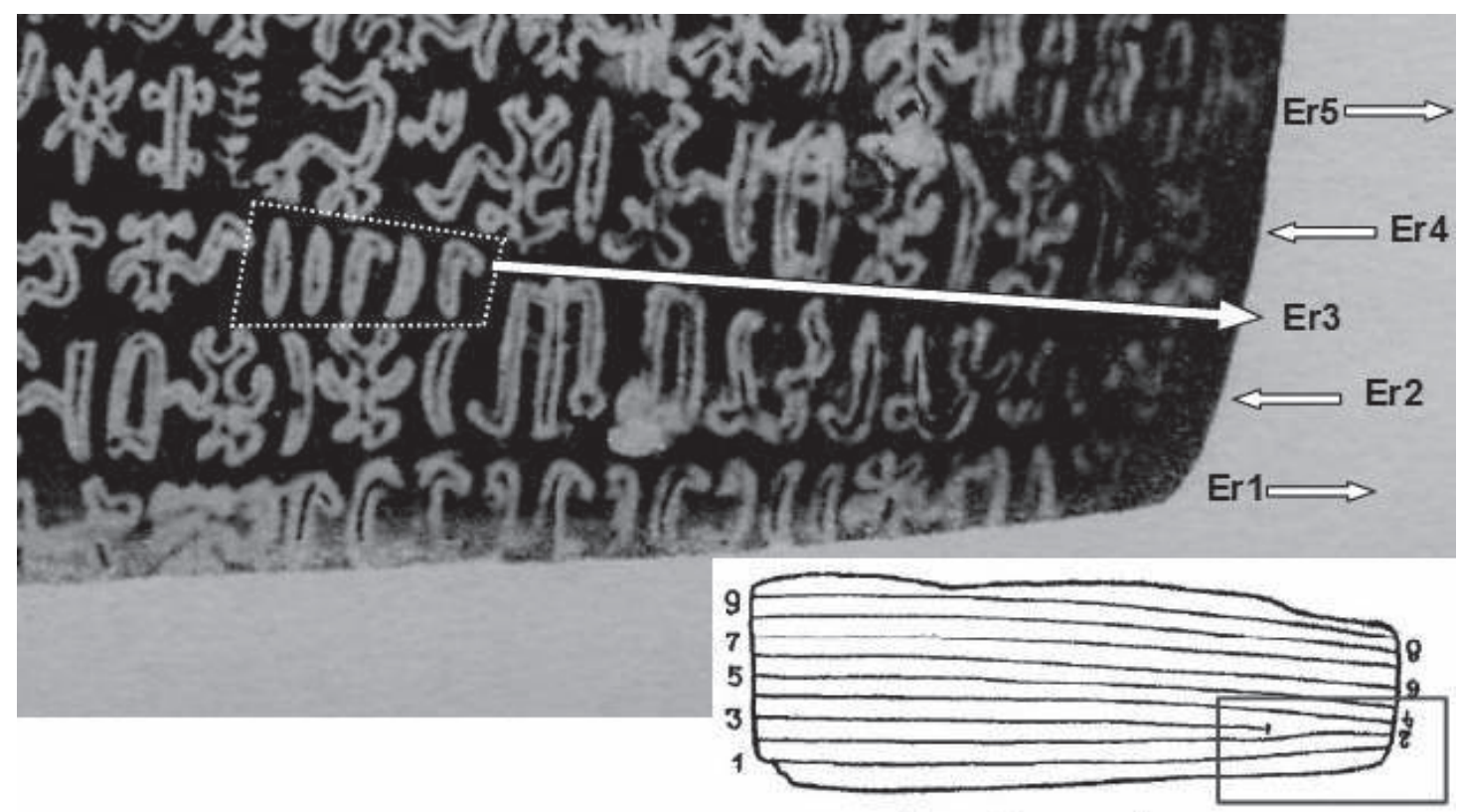

Text $\mathrm{E}$ recto $\uparrow$

The dashed line polygon in the middle left shows the fragment appearing after sequence alpha 8 and which finishes line Er3, Barthel's (1958) coding: 022-022-063-041-063*.

The insert in the bottom right shows the reproduction of the physical appearance of the recto side of tablet « Keiti » (image from Melka [2008] after Barthel [1958]).

The small rectangle in the far bottom right indicates the area of the tablet shown on the photograph.

FIGURE 2. - Fragment of the photograph of the original tablet (from Chauvet [1935] after Lavachery [1933]) showing the truncation of line Er3 
In the authors opinion the above mentioned circumstances strongly suggest that the meaning of glyph 385 should be connected with those that succeed it, that is sequence alpha 9. And should be treated as part of sequence alpha 9-alpha and is presented as such in Table 1 .

\section{On sequence alpha-beta}

This sequence is always composed of three glyphs. The first glyph of this sequence is an anthropomorphic figure holding something that resembles a "shield " or a "pierced artifact ». In accordance with Barthel (1958), this glyph in sequences alpha 1 and 2 is given as 300.024 and in sequences alpha 3 to 10 as $300.028 x$. Glyph 024 is very similar to glyph $028 \mathrm{x}$, the only difference being that glyph 024 is round at the top, whereas glyph 028x has a small cleft at the top (Table 1). From their occurrence in the sequence alpha 1-10 we can conclude that both glyphs are allographic variations. It is not easy to confirm this allographic relationship on other tablets, because glyph $028 x$ occurs only 5 times throughout the whole corpus outside of tablet E. In one case, line $\mathrm{Hr} 6$, it appears in a passage parallel to line $\operatorname{Pr} 6$, in which it is replaced by slightly altered form of 024 - 024a (figure 3). Adding this case to the equal position of those two glyphs (028x and 024) in the sequence alpha 1-10 (Table 1) it is safe to claim that $300.028 \mathrm{x}$ is regularly present throughout every alpha 1-10 sequence.

The next two glyphs in sequence alpha-beta are 004.430 and $022.380 y$. The glyph 004.430 occurs in every case except for alpha 6, where in its place there is only glyph 004 . The glyph $022.380 y$ occurs in every case except for the sequences alpha 3,6 and 9. In those cases it is replaced by a glyph 022 .

The important thing about the rongorongo tablet "Keiti " is that the copies made prior to its destruction show not only the sequence of glyphs but also their arrangement on the tablet. A high quality photograph of the original object was published by Lavachery (1933: Plate 2) (figure 2$)^{1}$. This allows us to look at the glyphs in context of their place on the tablet and draw some additional conclusions from their placements, as was shown above for the beginning of sequence alpha 9 and as will be argued later on for the nature of sequence alpha-gamma.

Sequence alpha 3 runs through the end of line Er1. The glyph 022.380y attested from other alpha sequences is here truncated to the form 022 , however the next glyph comprising the sequence alpha 3 gamma is not spared but written as the first glyph of the next line Er2. This suggests that, when it is repetitive, glyph $022.380 \mathrm{y}$ can be truncated to 022 without losing its meaning, whereas sequence alpha gamma (in this case 203s) seems to be unique and therefore has to be written in full. Such reasoning would explain why it was not compromised at the end of the line but moved to the next one.

In a similar way sequence alpha 6 runs through to the end of line Er2. In this case both glyphs 004.430 and $022.380 \mathrm{y}$ are truncated to their respective first half, glyphs 004 and 022 . Whereas sequence alpha 6-gamma is again spared truncation and given full needed space at the beginning of line Er3. This is in accordance with what happens in sequence alpha 3. Since glyphs 004.430 and $022.380 y$ are not variable, in this specific context they can be written as only 004 and 022 and still be read by a trained person in the proper way. Again, sequence alpha-gamma is moved to the next line, suggesting that it is not suitable for abbreviation (see figure 1 for both cases).

Sequence alpha-9 is not at the end of a line, instead, it opens line Er4. However, Er4 proceeds after line Er3, in which case the scribe performed radical space saving by wedging line $\mathrm{Er} 3$ between Er2 and Er4 (figure 2). It might be speculated that while beginning line Er4, the scribe still had in mind the need to save some space and therefore truncated glyph $022.380 \mathrm{y}$ to 022 .

One should take note of two more details that might be used against the notion of uniformity of sequence alpha-beta. In sequence alpha-7 the glyph 004.430 is given as $004.430 y$. In which "y " denotes apparent opposite orientation of the gaping mouth of the glyph 430 (CEIPP, 2005). This difference is seen only with greater attention and is most likely and allograph of 430.

In sequence alpha 9, although Barthel gives transcription 004.430 , it is probably wrong, as the glyph in question is most likely 004.630 , i.e. the gaping mouth is replaced by the beak-shaped mouth, this again seems to be an allograph in the presented context. It is of notice that these head shapes have also been considered allographs

\section{8x}

\section{Hr6}

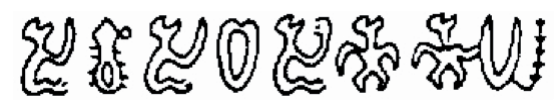

$\operatorname{Pr} 6$

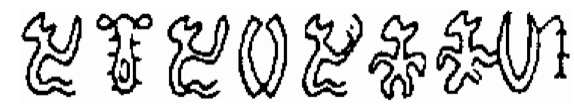

$024 a$

Figure 3. - Parallel texts between lines Hr6 and Pr6 show allographic relationship between glyphs 028x and 024a 
by another author in different contexts (Pozdniakov, 1996: 298).

If the above described reasoning is accepted, then glyphs 004 and 022 that we observe in sequences alpha 1-10 are context-dependent allographs, in the guise of abbreviations of glyphs 004.430 and $022.380 y$. Therefore one may conclude that sequence alpha-beta, transcribed in full as $300.028 \mathrm{x}-004.430-022.430 \mathrm{y}$, is the same and has the same meaning in every sequence alpha 1-10.

\section{On sequence alpha-gamma}

This sequence forms the last glyph of sequences alpha $1-10$ as identified by Melka (2008). This glyph is an anthropomorphic figure based on glyph 200. As we see in the cases of sequences alpha 3 and 6 this glyph is not compromised for abbreviation, therefore we might think that every time it occurs in sequence alpha 1-10 it has similar but different meanings that cannot be abbreviated (for example different variations based on the same proper name or common noun). Based on such an expectation it is curious to see that sequence alpha-gamma is, in a few cases, identical. Glyph 203s occurs in alpha 3,4,6 and 7 (plus bare 203 in alpha 5 and 8$)^{2}$ (Table 1). Those two observations do not go well together, which leads to the conclusion that sequence alpha-gamma is probably longer (as already mentioned, Melkass analysis was based on similarities, so by assumption it could detect alternations only in the middle of repeating sequences and not at their ends). Judging from the visual appearance of the lines it seems probable that, for example, sequence alpha 6-gamma should include also the succeeding glyphs 005t-678 (figure 1). Or that sequence alpha 5-gamma should include the succeeding compound 004?.062? (figure 1). Such a solution seems plausible. However, without clear indications, understanding the scribe's intentions for sequence alpha-gamma is confined to guesswork. Such guesses are not included in the Table 1.

\section{Proposed meaning of sequence alpha 1-10}

Proper astronomical observations are a primary concern in cultures that use a lunisolar calendar. This was also true for the Rapa Nui (Edwards and Belmonte, 2004). As we can see from the example of tablet "Mamari", some rongorongo tablets were used to record such observations or calendrical instructions. It is conceivable that "Mamari " tablet is not the only rongorongo artifact which deals with astronomy. Tablet "Keiti " (at least its recto side) might also be interpreted as containing, at least, some astronomical record/s.

Each sequence alpha 1-10 starts with a pair of crescents sometimes accompanied by one or two anthropomorphic figures (sequence alphaalpha). In the Rapa Nui calendar every night of the month has its own individual name, except for six and five kokore "nameless " nights that occur respectively before and after the full moon (Guy, 1990). The most prominent pair of nights that share some relationship are the two intercalary nights Hotu and Hiro, which are added to the basic 28-night Rapa Nui month, in order to keep-up with the natural moon phases of 29,5 nights per month (Guy, 1990: 140). Hotu and Hiro are probably the last glyphs of the identified lunar calendar of the tablet "Mamari " (Guy, 1990: 145).

In my view it is quite probable that the two crescents of sequences alpha-alpha are a depiction of Hotu and Hiro, with the first crescent depicting Hotu and the second one depicting Hiro (Hotu being the first intercalary night which is inserted before the full moon and Hiro being the second intercalary night added after the full moon). The alternating orientation of two crescents, glyph 040 facing right and glyph 041 facing left, can be then interpreted as an instruction on whether or not this particular night (Hotu or Hiro) should be included in the respective month. The whole sequence alpha would then describe one month and sequences alpha 1-10 would describe ten consecutive months. If we were to assume that the crescent facing right (glyph 040) in the place of Hotu means " add Hotu to this month " and the crescent facing left (glyph 041) in the place of Hotu means "don't add Hotu to this month", and the same for Hiro, then we would arrive with the list of ten consecutive months, their length in nights, and information on which intercalary night is added, or not added to the basic 28-night month (Table 2).

If we run this assumption through all ten alpha-alpha sequences we end up with 295 days (nights), a number which is approximately the length of ten 29,5-day lunar months (Table 2). This also gives additional support for the initial assumption.

With such a notion in mind, the meaning of the whole alpha sequence can be hypothesized. If, for example for the sequence alpha 1 , the alpha-alpha string means " add night Hotu and don't add night Hiro " (040.300-041-300y), then the string alpha-beta could mean " to the month of " (300.024-004.430-022.430y) and the glyphs of alpha-gamma could mean, for

2. In the case of alpha 6 Barthel appears to have made another mistake as he identifies the glyph here described as alpha 6-gamma as 203s whereas it should rather be 203 . 


\begin{tabular}{|c|c|c|c|}
\hline \multicolumn{2}{|c|}{$\begin{array}{l}\text { sequence } \\
\text { alpha-alpha }\end{array}$} & \multirow{2}{*}{ 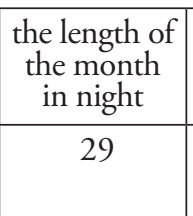 } & \multirow{2}{*}{\begin{tabular}{|r|}
$\begin{array}{r}\text { proposed } \\
\text { meaning }\end{array}$ \\
$\begin{array}{r}\text { add Hotu } \\
\text { don't add Hiro }\end{array}$ \\
\end{tabular}} \\
\hline alpha-1 & ॠ号 & & \\
\hline alpha-2 & ( & 30 & $\begin{array}{l}\text { add Hotu } \\
\text { add Hiro }\end{array}$ \\
\hline alpha-3 & 00 & 30 & $\begin{array}{l}\text { add Hotu } \\
\text { add Hiro }\end{array}$ \\
\hline alpha-4 & & 29 & $\begin{array}{r}\text { don't add Hotu } \\
\text { add Hiro }\end{array}$ \\
\hline alpha-5 & ब名 & 30 & $\begin{array}{l}\text { add Hotu } \\
\text { add Hiro }\end{array}$ \\
\hline alpha-6 & Al & 30 & $\begin{array}{l}\text { add Hotu } \\
\text { add Hiro }\end{array}$ \\
\hline alpha-7 & M & 29 & $\begin{array}{r}\text { don't add Hotu } \\
\text { add Hiro }\end{array}$ \\
\hline alpha-8 & D) & 28 & $\begin{array}{l}\text { don't add Hotu } \\
\text { don't add Hiro }\end{array}$ \\
\hline alpha-9 & 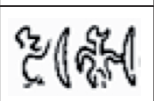 & 30 & $\begin{array}{l}\text { add Hotu } \\
\text { add Hiro }\end{array}$ \\
\hline alpha-10 & Al & 30 & $\begin{array}{l}\text { add Hotu } \\
\text { add Hiro }\end{array}$ \\
\hline & & \begin{tabular}{|c|} 
average \\
month length: \\
29,5 nights
\end{tabular} & \\
\hline
\end{tabular}

The ten months are arranged in a way to approximate synodic month.

TABLE 2. - The length of consecutive months in Rapa Nui calendar

example, "January " (206.063) or any of the proper Rapa Nui names for one of the months. The whole sequence would run: "Add night Hotu and don't add night Hiro to the month of January ", and so on and so forth through the whole alpha sequences. In this scheme, however, the meaning of the anthropomorphic figures of some alpha-alpha sequences would be unknown. Although it should be pointed out that there is an apparent similarity of those figures to the anthropomorphic figures accompanying glyphs 041 in the so called heraldic sequences inside the "Mamari" calendar (figure 5B) (Guy, 1990). Guy (1990: 143) hypothesized that they signify an act of measurement or observation.

Of course this is only one of possible interpretations for the alpha sequence within the framework of the proposed scheme for Hotu and Hiro calculations. For example, one could interpret the whole sequence alpha-alpha as a se- masiographic representation of a month name, which consists also of the Hotu/Hiro information (such an idea would also need to extend some of the alpha-alpha sequences to the glyphs before them so they would be distinguishable from each other, in Table 2 the sequences alpha 3-alpha, alpha 6-alpha and alpha 10-alpha are identical). The meaning of sequences alpha-beta could be then something like " of the year of " and alpha-gamma would be the name of the year, for example " the year of King X ". The overall meaning could be: "The January of the year of King X had intercalary night Hiro but didn't have Hotu ».

Many similar speculations are conceivable while still suiting the discussed pattern. Only two seemingly most likely are given here but other ones can also be considered.

\section{On the sequence gamma $1-10$}

This sequence, as stated by Melka (2008: 167), repeats itself ten times on the recto of tablet $\mathrm{E}$ (figure 1). Although, there might be possibly two additional occurrences of these sequence: partially erased starting the line Er1 and one somehow modified (inverted?) in the line Er3, between sequences alpha 7 and alpha 8 (figure 1).

The sequence gamma 1-10 consists solely of the core glyphs 004.430-022.380y. Sometimes the initial glyph is given by Barthel (1958) as 004.431 (gamma 4 and 5). The interpretation of those two glyphs as 431 instead of 430 seems to be highly subjective, if not a misprint. In one case, glyph $380 y$ is given as $430 y$ (gamma 10), again both glyphs are similar and their identification as one or the other can be subjective, especially because the glyph in question is partially erased. Were it not for Barthel's (1958) transcription, the author of this work would consider identifying this glyph as 380y (Table 3).

However, in three instances similar differences between glyphs seem to be more significant than the epigrapher's minutia mentioned above. This are when glyph 430 is replaced by 670 , in sequences gamma 9 and 10 , and glyph $380 \mathrm{y}$ is replaced by 460 in sequence gamma 3 . We do not know whether these differences were of any significance to the scribe. It is clear however, that all the gamma sequences are very similar (Table 3). What's more, sequence gamma is obviously the same sequence that forms the alpha-beta string. Alpha-beta would then be glyph $300.028 x$ plus sequence gamma.

Consequently it would be logical to infer the meaning of sequence gamma; or part of it (following the proposed scheme), as " month " (rapanui marama (Englert, 1948)) or, following second proposition as "year" (rapanui matahiti (Du Feu 1996: 208)). But even if it would in- 
deed mean one of these we do not know whether it is written as a logogram or as a phonogram, admitting that some degree of speech is involved in this area.

Further relaxing in speculations we can notice that the word matahiti would follow the glyphs in syllabic matter: 4 syllables for 4 glyphs. If one accepts that glyph 670 (or 430) represents a frigate bird, then the reading of this glyph as "TA " would be in accordance with previous proposition by Guy for the reading of other frigate-like glyph 600, which was based on the first syllable of the word taha "frigate " (Guy, 1990: 144). If we consider glyph 004 as a representation of an obsidian spear-head, rapanui mataa (Routledge, 1919: 123), then the first syllable of this word would be very likely the source for the reading of 004 as « MA ». Note that this proposed reading of compound 004.430 as "MA.TA " would be in accordance with other astronomical interpretations of the sequence gamma 1-10, such as $m a-$ ta-me-a « Mars » or ma-ta-ri-ki « Pleiades » (Du Feu, 1996: 202).

\section{On the 28-night month}

\begin{tabular}{|l|l|}
\hline $\begin{array}{l}\text { Sequence } \\
\text { gamma-1 }\end{array}$ & $004.430-022.380 y$ \\
\hline $\begin{array}{l}\text { Sequence } \\
\text { gamma-2 }\end{array}$ & $\begin{array}{l}\text { Sequence } \\
\text { gamma-3 }\end{array}$ \\
\hline $\begin{array}{l}\text { Sequence } \\
\text { gamma-4 }\end{array}$ \\
\hline $\begin{array}{l}\text { Sequence } \\
\text { gamma-5 }\end{array}$ \\
\hline $\begin{array}{l}\text { Sequence } \\
\text { gamma-6 }\end{array}$ \\
\hline $\begin{array}{l}\text { Sequence } \\
\text { gamma-7 }\end{array}$ \\
\hline $\begin{array}{l}\text { Sequence } \\
\text { gamma-8 }\end{array}$ \\
\hline $\begin{array}{l}\text { Sequence } \\
\text { gamma-9 }\end{array}$ \\
\hline $\begin{array}{l}\text { Sequence } \\
\text { gamma-10 }\end{array}$
\end{tabular}

The third column gives Barthel's (1958) transcription. Proposed meaning for the sequence: « month ". TABle 3. - Sequence gamma 1-10

According to the proposition outlined in this work, sequence alpha 8 would signify a mon- th without any intercalary nights, namely a 28-night month. The presence of this month is of considerable note as it might provide a falsification for the entire hypothesis, which will be discussed later. The important thing that should be noted is the sequence that appears after alpha 8. It is 022-022-063-041-063* (figure 2). This is the only case where the crescent glyph appears on tablet E's recto side outside of the alpha 1-10 sequences, namely the left facing crescent 041 . Taking into account what is written above about this glyph and its position after the only monthdenotation sequence which does not stipulate to add any additional night to the month in question, we may speculate the interpretation of the whole sequence 022-022-063-041-063* as follows: " don't add night here " or, more specifically " this is the month, to which no additional night should be added".

\section{Additional structural observations}

Except for sequence alpha 1-10 and gamma 1-10 there is another recurring sequence identified on the recto side of tablet "Keiti ». It is the sequence named beta 1-7 (figure 1) (Melka, 2008: 167), whose core glyphs can be transcribed as 205s-x-005 (where $\mathrm{x}$ stands for null or one or two non repetitive glyphs). The relationship of this sequence with the proposed calendrical instructions (if there is any) is not clear and no plausible speculation will be given by the author.

The last feature of note is the frequent presence of various forms of the lozenges glyph 002. Similar to the recto side of the "Mamari " tablet, where a high abundance of lozenges follow the identified lunar calendar, here they are also present with putative lunar month instructions. Their meaning is unknown but their presence in both cases suggest that they are in some way associated with astronomical observations. On the " Jaussen list " they appear a few times most notably as Matariki « Pleiades» (Brookman, 2007). Altogether there are 12 of them on the recto side of tablet E (13 if you also count the somewhat similar glyph 118 preceding sequence alpha 5).

\section{Discussion}

The interpretation of certain glyph sequences on tablet "Keiti " outlined in this article is only a speculation and should be treated as such. The proposed meanings of sequence gamma 1-10 or particular parts of the alpha 1-10 sequence are based on educated guesswork, built on the previous research of Barthel (1958), Krupa (1971), Guy (1990, 1992), Berthin and Berthin (2006) and Melka (2008). However plausible this might seem, it is important to stress that such an 


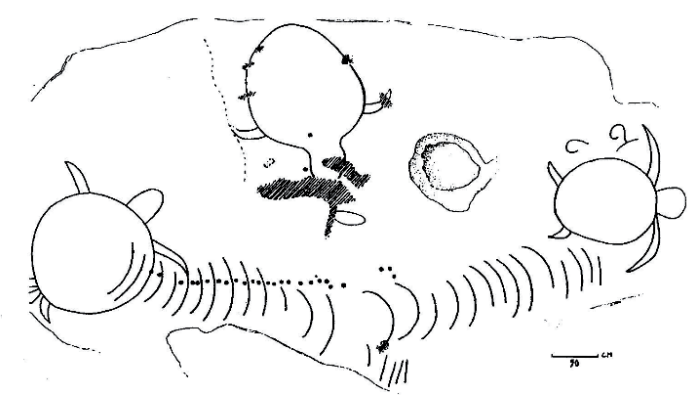

FIgURE 4. - Engravings on papa mahina rock near Ahu Ra'ai shows 28 crescent-shaped lines (reproduced from Belmonte and Edwards [2007: 84] original tracing in Lee [1992: 180])

interpretation of the above mentioned sequences brings along its baggage of doubts.

From ethnographic data we know that the ancient Rapa Nui calendar consisted of 12 regular months and included a $13^{\text {th }}$ month during the leap year (Guy, 1992) (if the calendar is designed to approximate 29,53 day lunar months then we might expect to have a 13 th month every third year, as the solar year is approximately equal to 12,36 lunar months). There are only ten sequences on tablet $\mathrm{E}$ that are interpreted here as month instructions. This difference can be explained in various ways. First, the interpretation of sequence alpha 1-10 as months could be wrong and that is why it does not relate well to the real calendar. Second, we can speculate that the calendar presented on tablet $\mathrm{E}$ is in some way truncated and was continued on another tablet, now lost (this would require considering side verso of Tablet $\mathrm{E}$ not as a continuation of side recto, but as a separate text). Therefore it would just follow only the first 10 months of a year. A third option; since the presented ten months have a mean length of 29,5 days, they can be used per se as a rule for month length approximation based on a 10 -month period. This means that after the tenth month finishes, an ancient Rapa Nui astronomer would interpret how many nights he should add to the next months, by starting the ten month cycle again (sequence alpha 1 would be used for the eleventh month, alpha 2 for twelfth, and alpha 3 for the first month of the next year, and so on with a two month shift every year). However, this would mean that the $13^{\text {th }}$ month of the third year would have to have 32 days to keep up with solar year, which is unlikely for a system designed around the moon phases (the leap month could be 30 days long, but then solar year approximation would not be very good). Yet another possibility is that the length of the last two months of the year were in some way fixed (to 30 days) and known to such extent that writing them down on a tablet was considered unnecessary or redundant. Or, the ta- blet in question presents some kind of historical account of some event that happened in specific months and as soon as it is well described which months are in questions the next ones (historically less important) are not mentioned (note that many more glyphs appear after sequences alpha 9 and 10 than after alpha 1-8). Those are just few of many plausible explanations, which merit further attention in the future.

Another point of doubt is the way the actual Rapa Nui calendar worked. It should be stressed that the model proposed by Guy (1990) of a 28-night based month to which one or two intercalary nights were added is only a hypothesis, drawn from the comparison of three ethnographic sources which list the names of the days of the month (Thomson, 1891: 546; Metraux, 1940: 50; Englert, 1948: 311-312). From these, Englert lists 28 days, Thomson 29 days and Metraux 30 days. Thomson lists Hotu but doesn't list Hiro, Englert lists Hiro but misses Hotu and one other night, Metraux lists both Hotu and Hiro. Guy (1990) proposes to resolve those differences by stating that a traditional Rapa Nui month could have consisted of a basic 28 nights to which one or two intercalary nights, Hotu and Hiro, could be added so as to achieve a mean length of 29,5 days. According to him: « < Hotu> may be missing from Englert's list because his informants gave him the basic 28-day month without its intercalary nights "(Guy, 1990: 139). However, other possibilities are worth considering. For example, we can use Occam's razor and state that in Englert's list there is some kind of a mistake and he omitted one or two nights. In such a case we would be left with two ethnographical sources listing month lengths as 29 and 30 nights (Hiro would remain the only intercalary night). Simple alternation of such months would give us a calendar well approximating the synodic month of 29,53 days. There are, nonetheless, other indicators pointing towards number 28 as a base for Rapa Nui month length. First and foremost, the lunar calendar of tablet "Mamari", as identified by Barthel (1958: 242247) and Guy (1990) has 30 nights, but the last two nights from the line $\mathrm{Ca} 9$ are clearly separated by three additional glyphs from the cluster of 28 nights from the lines Ca6-8. Thus the list of nights from the "Mamari " calendar could be best described as $28+2$. It is precisely for this reason combined with ethnographic data that pushed Guy (1990) to hypothesize that the last two crescents from the "Mamari " tablet are a representation for Hotu and Hiro. Another case, very worthy of mention, is the rock engravings which are found on Easter Island near Ahu Ra'ai (figure 4). On the rock, whose native name is papa mahina " rock of the moon ", we can find incised petroglyphs in the form of three sea turtles. Among them is a string of 28 crescents, 
most likely representing a lunar cycle (Edwards and Belmonte, 2007: 84). Thus, we can argue that there are two native " documents " which are compatible with the basic 28 night month. It could be then treated as an additional support for Guy's (1990) hypothesis, which places the 28 night lunar cycle at the core of the ancient Rapa Nui calendar.

In the hypothesis presented in this article the orientation of a crescent-shaped glyph 040/041 is important. It is argued that when placed in the sequence alpha 1-10 glyph 040/041 denotes either insertion or omission of intercalary night. We can try to evaluate the idea of the importance of the orientation of glyph 040/041 by looking for relevant passages in other rongorongo texts. Pozdniakov (1996: 301) presents a parallel passage shared between "Aruku Kurenga ", "Mamari ", " Great Santiago " and " Great St. Petersburg " tablets, which include a sequence of four consecutive moon glyphs (figure 5A). The way in which moon glyphs alternate their orientation in different examples of this parallel text suggest that the orientation of the glyph 040/041 is not relevant. On the other hand we know from the "Mamari » calendar that in the lines Ca6-9 glyphs 040 denote the count of one night and glyphs 041 never do that but instead are part of the " heraldic sequences " presumably denoting observation of the moon (Guy, 1990: 143) (figure $5 B)$. It is hard to draw any conclusive opinion on the importance of the orientation of moon glyphs in rongorongo texts based on these two examples. With our current very limited understanding of rongorongo system we are pressed to say that, at least at present, it seems that sometimes the orientation matters and sometimes it doesn't.

Yet another point of doubt is the pattern of month's number of days. Although the mean length of ten listed months is 29,5 days (Table 2 ), the mean length of any two neighbouring months may vary well beyond the natural variation of 29,3-29,8 days. This creates concerns of astronomical as well as ethnographic significance. There is no Rapa Nui ethnographic data known to the author that would confirm or contradict the month length sequence presented in Table 2, however, if such data were to appear they could easily either falsify the presented hypothesis or give it additional credence. Unless the suggested months are not consecutive, which is also imaginable. This additional option should not be discarded a priori.

\section{Conclusions}

The interpretation of the contents of the recto side of the rongorongo tablet "Keiti " presented in this article seems plausible. Certain features of the tablet strongly indicate that part of its content is astronomical. So even if the outlined hypothesis is wrong, the genre of this side of the tablet seems to be the same as the one of tablet «Mamari ». Bearing this in mind, alternative astronomical interpretations of tablet $\mathrm{E}$ can be given. It is the author's conviction that informed speculation such as is presented in this work, along with scrupulous structural and statistical analysis of rongorongo texts, is crucial to

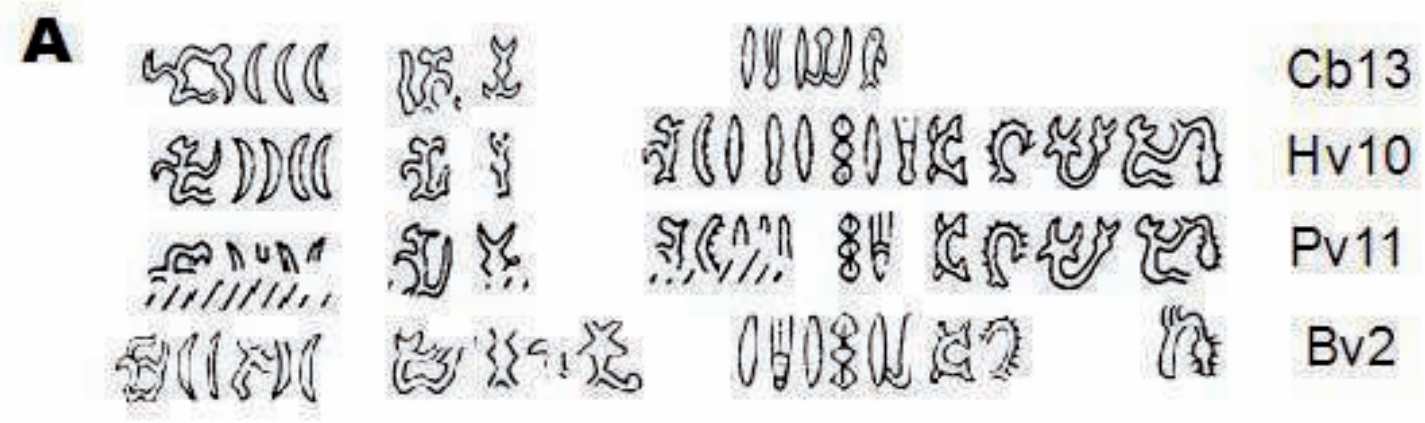

$\mathbf{B}$

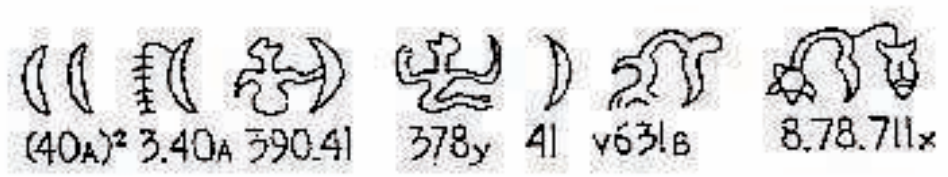

Ca8

A. Parallel texts between lines Bv2/Cb13/Hv10/Pv11 show seemingly random orientation of four crescentshaped glyphs either facing right - glyphs 040 or facing left - glyphs 041 . The space between various glyphs was artificially elongated for better alignment of parallel texts (images adapted from Barthel, 1958)

B. Fragment of the line Ca8 from the lunar calendar of tablet «Mamari ». Orientation of crescent-shaped glyphs is important as the right facing glyphs 040 are part of the night count and left facing glyphs 041 are part of the " observation " sequences intersected between the night count sequences (image from Guy, 1990)

FiguRE 5. - The importance of crescent-shape glyph orientation 
the advancement of our understanding of Easter Island's native script.

\section{Acknowledgements}

Many thanks for the generous help are addressed to Rachel Faiella (ectr, Venice), Tomi Melka (Parkland College, Champaign) and Paul Horley (cimav, Monterrey). The great editorial and professional comments made by them and by the three anonymous reviewers greatly improved the quality of this article.

\section{BIBLIOGRAPHY}

BARTHel Thomas, 1958. Grundlagen zur Entzifferung der Osterinselschrift, Hamburg, Cram, de Gruyter.

Belmonte Juan Antonio and Edmundo R. EdWARDS, 2007. Astronomy and landscape on Easter Island New hints in the light of ethnographical sources, BAR International Series 1607, pp. $79-85$.

Berthin Gordon and Michael Berthin, 2006. Astronomical Utility and Poetic Metaphor in the Rongorongo Lunar Calendar, Applied Semiotics 8 (18), pp. 85-98.

Brookman David Y., 2007. Easter Island Home Page, Jaussen list, Page 2. http://www.netaxs. $\mathrm{com} /-$ trance/jaus2.html (accessed Aug. 16, 2009).

Butinov Nikolai A. and Yuri V. Knorozov, 1957. Preliminary Report on the Study of the Written Language of Easter Island, Journal of the Polynesian Society 66 (1), pp. 5-17.

Cercle D'Études sur l'île de Pâques et la Polynésie (CEIPP), 2005. www.rongorongo.org (accessed Aug. 17, 2009).

Chauvet Stéphen-Charles, 1935. L'Ŷle de Pâques et ses mystères, Paris, Éditions "Tel " (English translation: Ann Altman [trans.] and Shawn McLaughlin [ed.], 2005. www.chauvet-translation.com [accessed Aug. 17, 2009]).

Du feu Veronica, 1996. Rapa Nui. Descriptive Grammar Series, London, Routledge.

Edwards Edmundo R. and Juan Antonio BeLMONTE, 2004. Megalithic astronomy of Easter Island: a reassessment, Journal for the History of Astronomy 35 (4), pp. 421-433.

EngLert Sebastian, 1948. La Tierra de Hotu Matu'a. Historia y Etnologia de la Isla de Pascua, Gramática y Diccionario del Antiguo Idio- ma de la Isla, Santiago de Chile, Imprenta y Edit. "San Francisco ", Padre Las Casas. Dictionary after www.rongorongo.org.

Fischer Steven R., 1992. Homogeneity in Old Rapanui, Oceanic Linguistics 31 (2), pp. 181190.

—, 1995. Preliminary Evidence for Cosmogonic Texts in Rapanui's Rongorongo Inscriptions, Journal of the Polynesian Society 104, pp. 303-321.

-, 1997. RongoRongO, The Easter Island Script: History, Traditions, Texts, Oxford, NY, Oxford University Press.

GuY Jacques B.M., 1982. Fused Glyphs in the Easter Island Script, Journal of the Polynesian Society 91, pp. 445-447.

-, 1985. On A Fragment of the Tahua Tablet, Journal of the Polynesian Society 94, pp. 367387.

-, 1990. On The Lunar Calendar of Tablet Mamari, Journal de la Société des Océanistes 91 (2), pp. 135-149.

—, 1992. À propos Des mois de l'ancien calendrier pascuan, Journal de la Société des Océanistes 94 (1), pp. 119-125.

—, 1998a. Un prétendu déchiffrement des tablettes de l'île de Pâques, Journal de la Société des Océanistes 106, pp. 57-63.

—, 1998b. Easter Island: Does the Santiago staff bear a cosmogonic text? Anthropos 93 (4-6), pp. $552-555$

-, 1998C. Probable Nature and Contents of the Santiago Staff, Rapa Nui Journal 12, p. 109.

—, 2003. Some Observations Drawn from the Putative Genealogy of Tablet G, Rapa Nui Journal 17 (1), pp. 42-43.

Harrison James Park, 1874. The Hieroglyphics of Easter Island, Journal of the Royal Anthropological Institute of Great Britain and Ireland 3, pp. 370-383.

Horley Paul, 2005. Allographic Variations and Statistical Analysis of the Rongorongo Script, Rapa Nui Journal 19 (2), pp. 107-116.

—, 2007. Structural Analysis of Rongorongo Inscriptions, Rapa Nui Journal 21 (1), pp. 25 32.

KRUPA Viktor, 1971. Moon in the writing of Easter Island, Oceanic Linguistics 10 (1), pp. 1-10. 
Lavachery Henri, 1933. Tablette Keiti, Bulletin de la Société des Américanistes de Belgique 10, pp. 101-102.

LeE Georgia. 1992. Rock Art of Easter Island. Symbols of Power, Prayers to the Gods. Los Angeles, California: UCLA Institute of Archaelogy.

MelKa Tomi S., 2008. Structural Observations Regarding RongoRongo Tablet "Keiti ", Cryptologia 32 (2), pp. 155-179.

—, 2009A. Some Considerations about the Kohau Rongorongo Script in the Light of a Statistical Analysis of the 'Santiago Staff', Cryptologia 33(1), pp. 24-73.

—, 2009B. The Corpus Problem in RongoRongo Studies, Glottotheory: International Journal of Linguistics 1/2, pp. 111-136.

MÉTraux Alfred, 1940. Ethnology of Easter Island, Honolulu, Bernice P. Bishop Museum Press, Bernice P. Bishop Museum Bulletin 160.

Pozdniakov Konstantin, 1996. Les bases du déchiffrement de l'écriture de l'île de Pâques,
Journal de la Société des Océanistes 103 (2), pp. 289-303.

Pozdniakov Konstantin and Igor pozdniakov, 2007. Rapanui Writing and the Rapanui Language: Preliminary Results of a Statistical Analysis, Forum for Anthropology and Culture 3, pp. 3-36.

Robinson Andrew, 2002. Lost Languages: The Enigma of the World's Undeciphered Scripts, A Peter Neuvramont Book. New York: McGraw-Hill.

Routledge Katherine, 1919. The Mystery of Easter Island. The Story of an Expedition, London and Aylesbury, Hazell, Watson and Viney, LD.

Sproat Richard, 2003. Approximate String Matches in the RR Corpus, http://www.cslu. ogi.edu/ $\sim$ sproatr/ror/ (accessed November 2, 2009).

Thomson William J., 1891. Te Pito te Henua, or Easter Island, Washington, Smithsonian Institution. 